\title{
Performance e Educação: uma função-educador agenciada por intervenções no urbano
}

Performance and Education: assemblage of a function-educator by the interventions in the urban

Juliana Soares Bom Tempo*

Universidade Estadual de Campinas

Resumo Propomos pensar a arte da performance e a educação como analisadores de práticas cotidianas. Utilizamos um processo performático intitulado Cariogamia e o risco do aborto, em duas intervenções urbanas: Campinas (SP) e São Paulo (SP) em 2012 e 2013. Tais performances atuaram em uma função-educador com potências mobilizadoras do cotidiano enquanto modos de vida pré-estabelecidos. A educação e a performance possuem aproximações ao se configurarem como práticas de experimentações vinculadas ao tempo presente e ao inesperado que produzem variações em signos pré-definidos pela cultura. Os processos de subjetivações trazem a urgência de abrirem-se, nesse plano de risco, ao novo e à invenção.

PALAVRAS-ChAVE: Performance, Educação, função-educador, signos, cotidiano.

Abstract We propose thinking about performance art and education as analyzers everyday practices. We use a performance process called Cariogamia and the risk of abortion, in two urban interventions: Campinas (SP) and São Paulo (SP), 2012 e 2013. Such performances acted in a function-educator with mobilizing powers of the everyday while pre -established ways of life. Education and performance are close to being configured as practice trials bound to the present time and the unexpected that produce variations in pre-defined signs by the culture. The processes of subjectivation bring the urgency to open up, in this risk level, to the new and to the invention.

KEYWORDS: Performance, Education, function-educator, signs, everyday. 


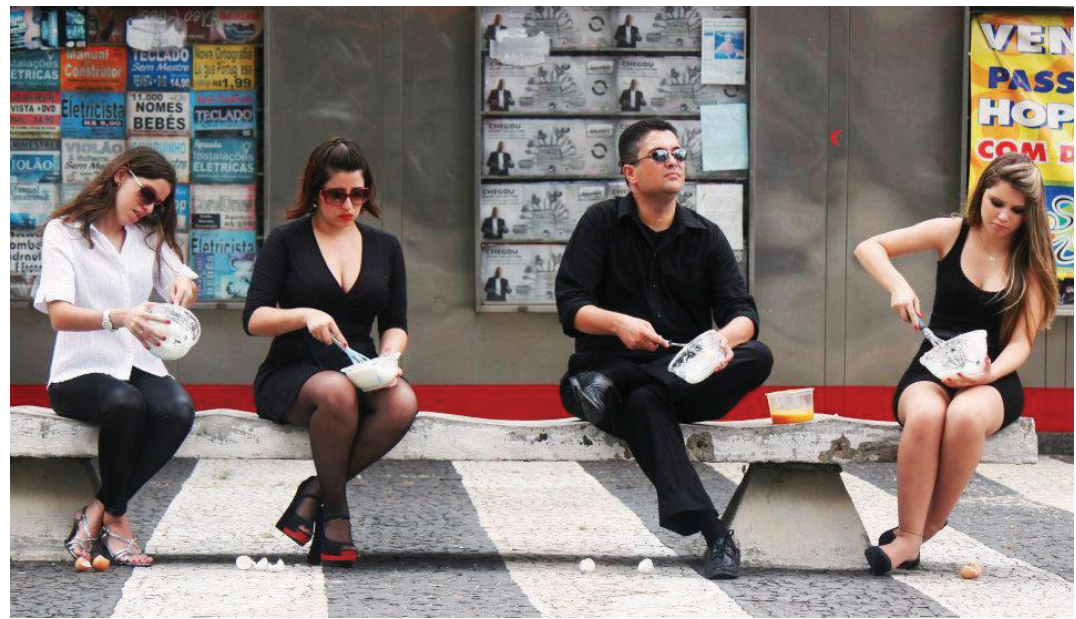

Figura 1: Cariogamia e o risco do aborto - Campinas/SP, 2012.

Performers: Juliana Bom-Tempo, Mariana Barbosa Morgão, Hugo de Almeida e Fabíola Martins. Foto: Cristiano Barbosa ${ }^{1}$

\section{Campos problemáticos}

O que pode a arte lançada como plano de problematização na área da educação? Frente a este questionamento, partimos em busca de um pensamento em educação que não formule regras de um raciocínio linear, e sim opere por experimentação, a fim de que possam ocorrer acontecimentos e novidades singulares.

Diante desse pensamento, o artigo aqui apresentado se vincula à arte da performance, aliado a este forte movimento artístico contemporâneo e aos efeitos produzidos, não só no contexto artístico, mas nas relações que agencia ao interferir no cotidiano.

Assim, lançamos mão da análise junto à criação e execução da ação performática Cariogamia e o risco do aborto, realizada em 2012 e 2013 a partir de duas intervenções urbanas na cidade de Campinas - SP e de São Paulo - SP (Brasil). A Figura 1 apresenta uma fotografia criada na relação com a ação em performance realizada no centro da cidade de Campinas - SP em 2012.

Esta performance - os ovos abortados antes de vingarem - foi concebida tendo em vista os processos criativos que acontecem na cidade, e que não chegam a vingar, abortam em uma relação de captura de ações e de práticas tidas como próprias para este contexto. Deste modo, o problema colocado na relação com a cidade pela performance Cariogamia e o risco do aborto, está em como transformar, neste campo de risco, abortos em encontros que aumentem a potência da vida, que movimentem as práticas desejáveis para um urbano que é a todo tempo capturado e pré-definido. 
O processo se dá no recorte de uma ação cotidiana normalmente realizada em um contexto íntimo e restrito, com finalidades e utilidades muito bem definidas, separando as claras das gemas de ovos de galinha e, em uma vasilha, transformamos as claras em neve. Ações próprias de narrativas cotidianas privadas, deslocadas para o contexto frenético de cidades com grandes fluxos de trânsito e de pessoas, realizadas no centro da cidade de Campinas - SP (2012) e na Estação da Luz em São Paulo - SP, vinculada, este último, ao Festival Baixo Centro ${ }^{2}$ (2013). As ações duraram 2 horas e 15 minutos e 2 horas e 30 minutos, respectivamente. A proposta de ação foi concebida por Juliana Bom-Tempo, que a realizou sozinha uma vez, antes das outras duas ações coletivas, nas ruas do centro da cidade de Campinas - SP, no início do ano de 2012. A busca por experimentar a ação coletiva se deu em função da temática da performance art ter sido abordada, durante o primeiro semestre de 2012, junto à discussões das relações entre a arte e a produção de outras sensibilidades que são criadas ao se intervir no cotidiano e no habitual, questões e posicionamentos que surgiram junto a disciplina ministrada por Juliana Bom-Tempo, no curso de Psicologia da Faculdade de Jaguariuna - SP. Diante disto, os estudantes da disciplina foram convidados para um programa com alguns encontros que seriam realizados extra-curso de Psicologia, durante tardes de sábados, em um sítio, próximo à cidade de Jaguariuna, cedido por uma das interessadas em participar, tanto com o propósito de apresentar um pouco do que seria a performance art, como também para experimentarmos, em oficinas e em duas intervenções urbanas, esses processos na prática. Na ocasião, foram ministradas quatro oficinas que incluiram as várias perspectivas de bases históricas da performance art, as relações entre performance e cotidiano, duas oficinas de preparações corporais e de criação, além da apresentação político-conceitual da ação Cariogamia e o risco do aborto. Essa foi a preparação que abriu o convite para execução da ação em performance. Os estudantes Mariana Barbosa Morgão, Hugo de Almeida e Fabíola Martins, do quarto período do curso de Psicologia, se engajaram nos processos de preparação e se dispuseram a desenvolver as ações junto à Juliana nos dois eventos supracitados.

Deste modo, procuramos neste texto analisar estas ações em performance como intervenções que ganharam a potência de uma função-educador, abalando os signos próprios da cidade e criando problemas para os modos de agir no contexto urbano.

\section{Performance e educação na experimentação do cotidiano}

As origens da performance art são pontos delicados na história da arte. Não há um localizador preciso dessas origens, já que não se trata de um novo domínio claramente ancorado nas artes visuais, na dança, no teatro ou na música. A performance art se constitui em um terreno movediço e mestiço, com hibridismos que forçam os limites das disciplinas, das formalizações artísticas e da própria arte enquanto um campo. Não podemos considerar que haja um consenso com relação a uma análise genealógica, já que a performance se fez, justamente, em movimentos de insubmissões e nas vontades de ultrapassar os domínios da própria forma de arte.

A respeito dessas várias perspectivas de afirmação do que seria um terreno originário da performance art, dentre as inúmeras obras que tratam da história, teoria 
e perspectiva crítica da performance arte, elencamos, nesse texto, as de Goldberg e de Schimmel. Diante disso, podemos citar Roselee Goldberg (2006), historiadora e crítica de arte, que publicou, na década de 1970, o livro que se tornou referência $A$ arte da performance: do futurismo ao presente. Nesse texto, a autora busca os precursores históricos da performance art e afirma que o que pode-se chamar de performance nos campos da arte ganhou grande importância durante o século XX, ao propiciar aos movimentos artísticos (futurismo, cubismo e minimalismo) a abertura a novas direções, a partir do questionamento das sedimentações e estagnações que o campo artístico experimentava.

De outra parte, Paul Schimmel em 1998, no catálogo intitulado Out of Actions, between performance and the object 1949-1979, dá ênfase às relações entre performance e artes plásticas. A partir de uma exposição com objetos ligados à processos performáticos, trabalha a relação entre as ações em performance e os objetos utilizados por ela. Nesse trabalho, Schimmel afirma que foi no pós Segunda Guerra Mundial que aconteceu uma reviravolta nas artes, uma desmaterialização do objeto artístico, uma primazia do ato.

As múltiplas variações e definições a cerca das origens da performance art e àquelas criadas pelo próprio performer ao longo do processo de criação e dos modos de execução, conferem à performance um caráter inespecífico, permitindo pensar, também, a própria atuação artística como extremamente diversa e feita nos entremeios dos campos de saber e das disciplinas já estabelecidas.

A partir desses variados modos de execução da performance, ações performáticas problematizam os limites colocados para os contextos de vida, trazendo aberturas para uma educação que se processe nos encontros com signos disparados pelas performances, desalojando as estagnações de signos fixados e pré-definidos culturalmente.

Diante desse campo problemático, ancoramos essa escrita em uma educação como operadora de aprendizagens que se dão nos entremeios das disciplinas, do currículo e do próprio cotidiano, ao se aliar a campos diversos, tais como os da performance art e também da filosofia contemporânea. Assim, mister construirmos um território para educação, que possa aproximá-la das práticas performáticas e da própria proposição estética da performance.

Destarte, como se processa a experiência do aprendizado? Essa questão baliza a conferência proferida na Faculdade de Educação da Universidade Estadual de Campinas - Unicamp durante o I Seminário Conexões ${ }^{3}$ por Luiz B. L. Orlandi (2011). Para ele, a experiência do aprendizado demanda da articulação do pensamento ao caos como uma constante do processo de aprender, criando abalos no já sabido e inseparável da vida. Assim, o caos emerge ao se agenciarem processos de aprendizagem, seja na própria condição cotidiana, na relação com o mundo, seja ao envolver-se junto ao aprendizado dos outros, tanto nas relações que se dão nas instituições escolares, quanto naquelas entre os que nelas não estão.

Orlandi, alinhado ao pensamento filosófico de Deleuze $(1987,1988)$ e Guattari $(1992,1995,1997,2002)$, propõe pensar a aprendizagem destituindo a edu- 
cação de seu lugar costumeiro de campo do saber. Neste deslocamento, a prática do educador estaria então ligada a sua "efetiva e atual participação na experiência do próprio aprendizado" ao se vincular ao campo problemático envolvido (ORLANDI, 2011, p. 148).

O aprender encontra-se além das estruturas institucionais de ensino ou da ideia de um modelo a ser seguido. Trata-se antes de um processo que ocorre nos encontros que forçam o pensar junto a campos problemáticos, isto é, junto àquilo que para cada um, numa determinada época, "faz problema".

De outra parte, para Virgínia Kastrup (2007), a aprendizagem está ligada a um campo de experimentação em uma prática relacional, já que concebe a aprendizagem como agenciamento com algo, alianças que ocorrem nos encontros. A aprendizagem, para a autora, é um processo de experimentação constante que impossibilita que o aprendiz cristalize hábitos. A aprendizagem torna-se produtora de si e do mundo, uma prática de invenção, aliada à possibilidade do aprendiz de problematizar, tornando-o sensível às variações dos processos vitais. $\mathrm{O}$ aprender produz então a diferenciação incessante da cognição: aprende-se por perda dos hábitos. Portanto, a aprendizagem apresenta-se como um desaprender, como uma abertura ao que ainda não se efetivou, àquilo que não se pode prever.

É nessa perspectiva experimental da produção de problemas, face às sedimentações formais dos corpos e do cotidiano, que pensamos a performance como um perturbador que agencia novos processos junto às intervenções e produz desestabilizações, por isso, abre a potencialidade de produzir aprendizagens, como um analisador das práticas educacionais, tornando visíveis não somente modos de funcionamento instituídos no campo da educação, mas aquilo que permanece subterrâneo nas práticas cotidianas e que se constituiria como problema vinculado à educação.

Diante disso, tanto a educação quanto a performance configuram-se como práticas inseparáveis de um aprendizado de si e de escapes às políticas de controle, ao se desvincular da ideia de uma educação para o sucesso e para o vencedor, da arte como sedimentação de escolas artísticas, da educação como solucionadora de problemas e da arte como representação do mundo, que produzem, em contrapartida, um encadeamento de decepções e fracassos diante da não efetivação das estabilidades prometidas, fracassos estes importantes ao processo de aprendizado.

Propomos pensar a educação e a performance suscitadas com a produção de modos de existir abertos aos acontecimentos e que passam a ser expressões atentas a toda sorte de encontros, carregando em si os signos do imprevisível, do incalculável, não se filiando unicamente a campos formais e estabilizados, mas criando alianças junto a forças ativas na afirmação da vida e do mundo.

As relações que se dão com a experimentação do mundo, das intensidades de sensações que atravessam os corpos, dos processos de aberturas aos encontros afetivos e dos acontecimentos da vida, constituem elementos presentes nas práticas performáticas, que, junto à educação, funcionam como analisadoras das práticas educativas e cotidianas. 
Os modos de vida atuais e as subjetividades que a eles correspondem formam, a todo tempo, paradoxos que se tornam complexos nos movimentos cotidianos. $\mathrm{O}$ dia-a-dia experienciado na vida doméstica, frente às tarefas, às negociações de tempo e afazeres daqueles que coabitam um mesmo território e que necessitam estabilizar os locais para o "bom funcionamento" destes, produz, nas nossas práticas diárias, a abolição de experimentações de outros modos de vida, valorizando o cálculo que engessa os corpos em atividades automatizadas, fortificando as divisões e os papéis sociais, em segmentaridades cotidianas.

Os objetos presentes nas intimidades e a rede de forças e tensões colocadas nos lares agenciam posturas corporais que criam a ilusão de segurança, com construções de muros, de redes de proteção e de visibilidades que controlam o cotidiano mesmo no que tomamos como nosso espaço privativo, produzindo medos em micropolíticas e em toda uma microgestão de pequenos medos (DELEUZE; GUATTARI, 1996).

Apesar de tais esquadrinhamentos, esses fluxos seguem desviando e escapando ao controle e ao cálculo. Mesmo diante de lógicas que tendem a configurar as existências cotidianas presentes na cultura capitalística ocidental contemporânea, que tendem a abolir as invenções de outras possibilidades de vida fugidias àquelas dadas como possíveis e desejáveis; mesmo junto a estas tendências, acontecem escapes, desvios de capturas, imprevisibilidades que se agenciam em micropolíticas moleculares e criam vazamentos na realidade que se pretende organizada.

A performance, ao intervir no cotidiano, ganha uma funcionalidade educativa, tal como tomamos a educação neste trabalho, produzindo experimentações e deslocamentos importantes para produção de novas relações com a vida, explicitando forças e tensões que encontram-se invisíveis nas nossas atividades diárias, que produzem afetações corporais e sensoriais, atuando violenta e silenciosamente em processos desvitalizantes e desvinculados da própria vida.

Acontece na relação entre as performances e os contextos, em que tais ações são executadas, o agenciamento de uma função-educador, tal qual formulada por Carvalho (2010), na medida em que a performance opera na tensão das ações cotidianas, abrindo esses modos de atuação ao estranhamento, "pois revolve o terreno das forças estabelecidas no campo da educação [...] para colocar a mostra as suas problematizações" (CARVALHO, 2010, p. 140).

Deste modo, a performance passa a operar na função-educador em articulações maquínicas, junto aos signos seja da arte, da cidade, do museu, do cotidiano, da educação. O conceito "maquínico" aqui apropriado foi cunhado por Félix Guattari (1992) e está ligado ao funcionamento que se dá através de comunicações expostas e sutis.

Um jogo de dentro e fora do corpo. Contexto-sensitivo em que a mensagem é emitida. Receptores corpóreos conectados em mensagens emitidas pela máquina. As máquinas sociais funcionam como Equipamentos Coletivos operando no núcleo das subjetividades, consciente e inconscientemente. 
Em assim sendo, há um processo de concorrência entre os componentes heterogêneos para a produção de subjetividades e de corporeidades. São os componentes vinculados às instituições tais como família, religião, arte, educação, saúde; os componentes fabricados pelas mídias e os componentes sutis de informatizações asignificantes, que nos atravessam em comunicações inconscientes da articulação entre componentes. No caso em questão: articulações entre cidade, corpos, ações e cotidiano.

\section{Processos de campo: Função-educador e as maquinações na relação com Cariogamia e o risco do aborto}
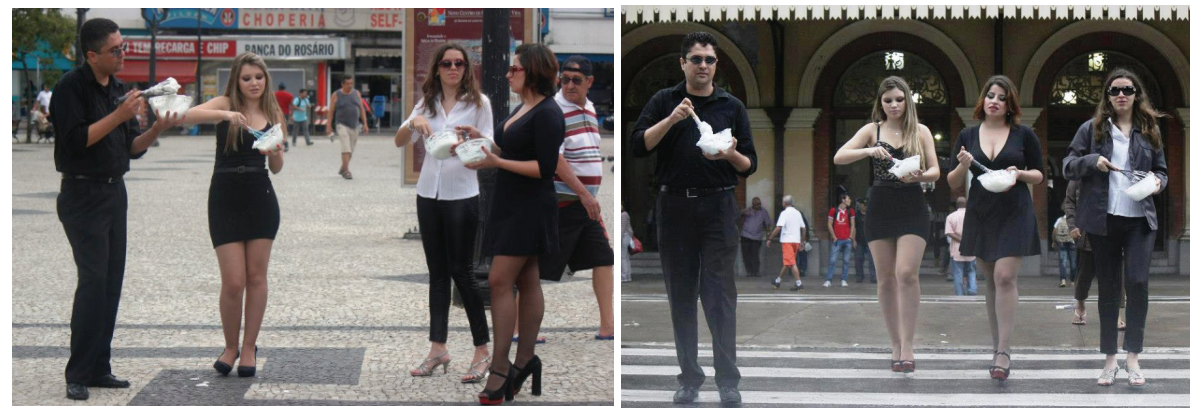

Figura 2: Cariogamia e o risco do aborto. Campinas/SP. 2012 (à esquerda). São Paulo. 2013 (à direita) Performers: Juliana Bom-Tempo, Mariana Barbosa Morgão, Hugo de Almeida e Fabíola Martins. Foto: Cristiano Barbosa

Uma praça do centro da cidade com pessoas, uma estação de metrô habitada por passantes, passantes parados, pessoas em trânsito. Comércio aberto, tempo nublado, chuva fina. Dispersões no espaço aberto, amontoados de gente nas portas. Arquiteturas modernas, antigas, praças, igreja, lojas, lanchonetes, carros, sinais de trânsito, faixa de pedestre, mulheres, crianças, senhores, cheiros de poluição, paisagens urbanas. Tal descrição pode ser facilmente identificada por pessoas que costumam andar pela cidade em um dia qualquer no período comercial. Uma descrição clichê do que se vê todo dia em qualquer contexto urbano, muito cotidiano, principalmente para as duas maiores cidades do Estado de São Paulo.

Três mulheres e um homem - maquiagens, salto alto, camisa, calça social, saias, meia calça, rendas, roupas pretas - atravessam espaços tipicamente urbanos portando vasilhas, batedores de clara em neve, uma caixa de ovos. Param na praça, na porta da estação. Olham, andam mais um pouco, param, decidem um lugar, um lugar qualquer, e colocam os ovos no chão. $\mathrm{O}$ homem agacha-se, quebra com muito cuidado um dos ovos, separa a clara da gema, descarta a gema e fica com a clara, levanta-se e começa a bater. Uma das mulheres faz o mesmo, levanta-se e começa a bater, para, olha, volta a andar, volta a bater. Outra e outra fazem o mesmo. Passam de pessoas passantes bem vestidas a batedores de clara em neve.

Uma ação comum para um contexto íntimo, uma narrativa que parte de um motivo e tem utilidades bem definidas para a culinária. Em receitas cotidianas a clara em neve é batida e adicionada a alguma mistura, um bolo, um chantili, um mouse de 
chocolate ou maracujá, uma massa para tortas salgadas. Nesse processo, não se costuma bater clara em neve simplesmente para bater clara em neve. É um meio e nunca um fim. Recortamos o meio e esticamos, não há começo, nem fim, apostamos no meio. A figura 2 nos apresenta imagens fotográficas produzidas nas relações com as ações executadas em Campinas/SP e São Paulo.

Como o contexto cotidiano de uma cidade entra em risco a partir destas ações? Quais desalojamentos de signos violentam a cidade com uma ação tão comum e tão estranha? Que tipos de máquinas corremos o risco de inventar nos movimentos fortes e constantes ao transformarmos claras em neve? Como a cidade é colocada em movimento? Tais perguntas pululam frente às ações que deslocam pessoas acostumadas com uma paisagem urbana que separa, de forma bem nítida, o espaço público das práticas próprias de contextos íntimos. É nesse sentido que pensamos uma produção maquínica como agenciadora de uma função-educador.

Carvalho (2010) nos convida a pensar a função-educador, a partir principalmente de proposições foucaultianas, nas subjetivações produzidas nas relações entre educador e educando, na própria constituição do sujeito no campo educacional, propondo funcionar na produção de sujeitos ativos e críticos no contexto escolar. Frente à contribuição do autor, nos propomos a produzir desvios contextuais e subjetivos do conceito em questão. Haveria potência nesse conceito para pensar a função-educador funcionando a partir de uma intervenção nas paisagens e narrativas urbanas?

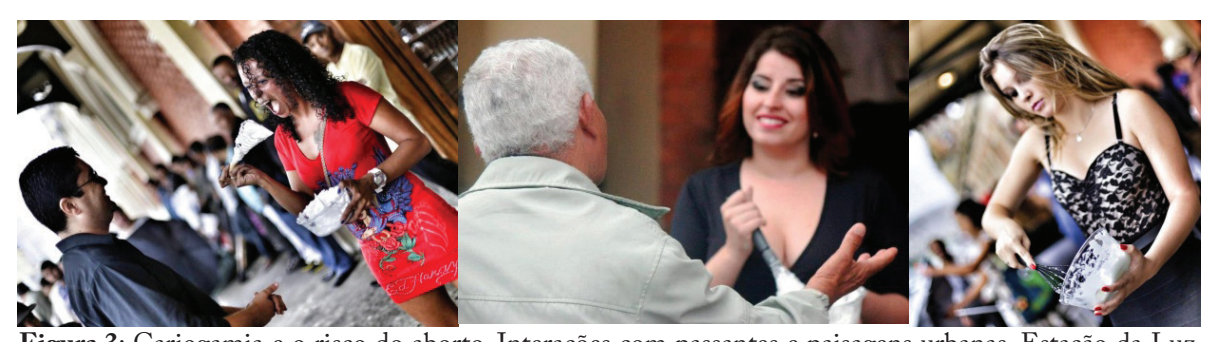

Figura 3: Cariogamia e o risco do aborto. Interações com passantes e paisagens urbanas. Estação da Luz. Festival Baixo Centro. São Paulo. 2013.

Foto: Cristiano Barbosa.

Ação: bater clara em neve. Contexto: o urbano. Como: trajes bem apessoados. Para que: pelo prazer inútil de transformar a clara em neve no fluxo da cidade.

Manifestações vêm à tona: "Até uma criança sabe que isso não tem sentido!"; "Isso não tem sentido!"; "Mas pra que vocês estão fazendo isso?”; "Vocês estão vendendo algum produto?"; "É um protesto contra o quê?"; "Hum, já sei, também faço isso na encruzilhada com pinga e velas, é tipo promessa, sei como é"; "Os jovens de hoje não se alimentam bem, tenho 76 anos e venho de Pernambuco, minha mãe fazia muito isso, mas os jovens de hoje só querem comer lanche, não comem inhame, eu comia ovo cru mesmo e era forte; hoje em dia, os jovens nem param em pé"; "Porque vocês não levam isso ali na lanchonete, fritam com tomate e orégano e, assim como uma coisa inútil traz pra gente comer"; "Adorei, parabéns!"; "Que coisa besta!"... 
A figura 3 apresenta imagens captadas junto a performance realizada na Estação da Luz da cidade de São Paulo, durante o Festival Baixo Centro. Nas imagens, estão apresentados enquadramentos que favorecem a explicitação do que aqui queremos evidenciar a respeito dos estranhamentos provocados com relação a uma prática reconhecida, como bater claras em neve, mas que, frente ao contexto urbano ao qual ela for inserida, abre a própria ação e os signos urbanos a outros sentidos.

A performance Cariogamia e o risco do aborto ganhou uma potência maquínica de intervenção no urbano agenciando uma função-educador?

Guattari (1992) propõe um novo pensamento sobre os processos de produção de subjetividade, a partir das espacialidades constituídas no contexto urbano e suas relações com a corporeidade. Particularmente, em um dos capítulos do livro $C a-$ osmose, intitulado "Espaço e Corporeidade", o autor coloca que as dinâmicas urbanas de trânsito, os fluxos de conexão dos corpos aos automóveis, a arquitetura dos prédios, as disposições das ruas, atuam diretamente nas configurações corpóreas e nos modos de estar na cidade.

Assim, diante destes aspectos diversos da espacialidade, há várias camadas coexistentes de espaços heterogêneos sobrepostos, que podem agenciar pontos de fuga da circulação preestabelecida no trânsito de veículos e criar espaços de lembranças, de imaginação, ou mesmo espaços musicais.

O autor propõe ainda outras possibilidades ao nos depararmos com paisagens que podem ganhar atributos estéticos, gerando composições afetivas e éticas, colocando toda a estratificação espacial rodoviária em segundo plano. Outro exemplo são as percepções dos espaços na atualidade, que podem se desdobrar em percepções antigas, sendo esse processo de recordação acompanhado por afecções presentes, criando impressões de forma inventiva.

A arquitetura da cidade, com seus prédios e construções, tem a funcionalidade de "máquinas enunciadoras" que produzem subjetividades abertas a conexões com outros processos de subjetivação vinculados à cognição e aos afetos. Assim, os espaços construídos produzem efeitos além do que vemos conscientemente e de como funcionam na cidade. "São essencialmente máquinas, máquinas de sentido, de sensação” (GUATTARI, 1992, p. 158).

Frente a isso, as configurações urbanas, os objetos presentes na cidade, as arquiteturas têm a potencialidade de funcionarem tanto como efeitos de universalização e homogeneização, quanto de liberações de processos de singularização coletivos e individuais.

Corpos e espaços construídos interagem produzindo existências efetivas e potenciais em zonas heterogêneas e caóticas, agenciando na cidade a funcionalidade de uma megamáquina. $\mathrm{O}$ autor amplia o conceito de máquina ao ligá-lo às dimensões desejantes, articuladas a aspectos econômicos, políticos, históricos, ecológicos, tal qual apresentado anteriormente neste texto. 
Guattari propõe um deslocamento da subjetividade para os componentes materiais enquanto subjetividades parciais, "a cidade, a rua, o prédio, a porta, o corredor [...] modelizam, cada um por sua parte e em composições globais, focos de subjetivação". O espaço construído é o disparador de processos orgânicos, subjetivos e comportamentais (GUATTARI, 1992, p. 161).

Espaços construídos e dinâmicas urbanas estão associados e possuem sentidos a-significantes, criando componentes sempre parciais e heterogêneos de subjetivação. Por esta razão, Guattari propõe uma redefinição das ligações de espaços construídos e dos processos de subjetivação, colocando-nos as dimensões políticas presentes na cidade, nas produções de corporeidades e de subjetividades.

Ao articularmos os processos de subjetivações aos pensamentos de Félix Guattari (1992), propomos transversalizar a produção de subjetividades entre humanos e inumanos, considerando forças visíveis e invisíveis, conscientes e inconscientes no exercício da função-educador. Esta não seria, portanto, uma relação específica entre humanos subjetivados, mas ganharia a funcionalidade de um agenciamento, articulando prédios, ruas, sinais de trânsito, pessoas, passantes, árvores, arquiteturas em que, frente a uma intervenção performática, sofrem abalados enquanto um cotidiano de signos legitimados em enunciados coletivos que fixam a cidade nas práticas tidas como próprias a estes contextos. Os prédios, as ruas, os corredores, os espaços configurados da cidade recebem novos movimentos, novos modos de relação com três mulheres e um homem bem vestidos à bater claras em neve, uma nova paisagem passa a ser composta frente a essa ação, que cria novas miradas, novas composições entre ruas, carros, sinais de trânsito, prédios, cidade. As cores dos prédios antigos da Estação da Luz de São Paulo passam a ser componentes de outras narrativas produzidas pelos encontros entre prédios, mulheres, homem, passantes, ruas, sinais, claras em neve; os sinais de trânsito e os largos que compõem as ruas e praças do centro de Campinas - SP são convocados a outras relações entre pedestres, carros, bancos e bancas de jornais, novas paisagens urbanas criam outras subjetividades nas relações que configuram as paisagens das cidades que receberam as intervenções.

A função-educador, proposta por Carvalho (2010), ganha, neste artigo, a funcionalidade de produções maquínicas que agenciam mobilidades de signos no cotidiano da cidade e nas relações com o urbano. Segundo o autor, para que se crie uma "transposição possível às formas de subjetividade ou condução, ela não pode abrir mão do componente experimental que associa a própria atitude como contraforça de todo alvo de regulação, regulamentação e gestão dos aspectos da vida" (CARVALHO, 2010, p. 130).

Assim, há uma proposta de, na função-educador, haver uma "atitude-experimental" na produção de "deslocamentos de subjetividades", seja nas relações contextuais da escola, como ele afirma, seja nos cotidianos urbanos, como propomos pensar a partir da intervenção performática.

Tal função-educador abre os territórios estabilizados pelas culturas escolares e urbanas a práticas inovadoras e às criações, tornando visíveis as problematizações 
que abalam e movimentam tais estabilidades, provocando relações polêmicas frente aos modos arbitrários de vida fixados nestes contextos, "colocando em questão os dogmatismos de todo tipo que cercam, bloqueiam e obnubilam os pontos de criação que requerem a confrontação sem pausa" (CARVALHO, 2010, p. 141).

Portanto, cria a abertura para a criação de novas relações e conexões no urbano, tanto entre os passantes, os signos fixados, quanto na própria paisagem da cidade. A função-educador atua como um acontecimento nas experimentações com os signos em busca de que, nos encontros que violentam os signos fixos do urbano, algo se movimente, crie problemas, saia do lugar sedentarizado.

\section{Considerações: Educação, signos e intuição em abalos fe- cundos de uma performance urbana}

Deleuze (1987) produz uma leitura que podemos aproximar desta perspectiva. Segundo o autor, nunca se sabe como uma pessoa aprende; mas de qualquer forma sempre aprende por meio de signos, perdendo tempo ao buscar a decifração destes, mobilizam, assim, os signos e produzindo aprendizagens, não pelo acúmulo e assimilação de conteúdos materiais objetivos. Estes conteúdos intelectuais são verdades limitadas, pois não são aprendidos por necessidades. À inteligência cabe compreender criticamente as funções dos signos no mundo. As aprendizagens se dão por outras vias.

O aprendizado configurando-se como uma busca tendo o presente como aliado. $\mathrm{O}$ importante nesta empreitada é o que não se sabe a princípio. Este processo não tem nem início e nem fim. Aprende-se progressivamente, com configurações momentâneas e decepções sofridas.

Um processo não linear que hora recua, sofre regressões e preguiça, também frágil de abertura do aprendiz para se sensibilizar aos signos. Para a sua ativação é preciso que haja encontros. Tais encontros promovem desvios, violências que desafiam as crenças e as leis prontas.

Acredita-se, por crença ou lei que o mundo objetivo traz o signo fixo e sedentário, impossibilitando qualquer desvio, ordenado pelas leis da linguagem. Crê-se que há uma correspondência direta do signo com o objeto, que produz estagnação dos processos de busca, pois estabiliza o mundo, impossibilitando tais aprendizagens.

Assim, a performace Cariogamia e o risco do aborto, ao intervir no cotidiano - no tecido de relações políticas, sociais e econômicas que se expressa fisicamente e subjetivamente - funciona como invenção aberta às instabilidades do presente em uma prática de tateio, de experimentação, de articulação e de deslocamento inesperado que entra em choque com as práticas cotidianas próprias da cidade, desvinculadas das imprevisibilidades ligadas à proliferação da vida, fazendo problemas ao que se pode fazer nos contextos públicos.

Para que a função-educador aconteça, há a exigência de um esforço para prevalecer a tendência de criação, que se vincula ao tempo em processos de aprendizagem. A invenção de si e do mundo está ligada ao tempo, e só se efetivará como produto 
das forças criadoras através das tensões permanentes com as repetições presentes no cotidiano. Assim, criação e repetição vivem em estado de captura mútua, sendo que a criação só se efetiva em processo inventivo na conexão entre as instabilizações vinculadas ao tempo e as repetições ligadas ao cotidiano.

A performance entra em contato com o cotidiano através de ações práticas e diretas, mobilizando as intermediações representativas, aliando-se com as tendências criativas presentes em um contato inventivo na experimentação do cotidiano.

A invenção se faz na dimensão prática de experimentação como condição de constituição tanto das subjetividades e da cognição, quanto do mundo. A cognição como invenção se faz na abertura para o novo, o inesperado, o imprevisível. Esse procedimento de abertura se dá com a potência de formular problemas, como função-educador de problematização do mundo.

A educação, nessa investigação, atua como campo a ser problematizado, dissolvendo distanciamentos com relação à produção estética da vida; ou seja, produzir uma educação vinculada às vulnerabilidades, tendo como analisador a performance Cariogamia e o risco do aborto que mobilizou as organizações rígidas do dia-a-dia e se aliou, por alguns momentos, às forças intempestivas de um tempo inventivo.

Tal performance articula-se à educação ligada a uma cognição criativa, que problematiza o mundo. Assim, não está pré-ocupada com soluções de problemas já colocados, mas com sua invenção de problemas e construção de linhas de soluções provisórias e finitas, já que se trata da vida como campo multirrelacional. A cognição aqui é pensada como movimento da própria vida, como multiplicidade heterogênea, que procuraremos intervir e ativar linhas de fuga ${ }^{4} \mathrm{em}$ combates ativos nos momentos em que somos capturados por lógicas que nos são impostas frente aos contextos cotidianos.

No trabalho com esta performance, os performers se abriram às instabilidades do presente, e o próprio trabalho exigiu que os performers criassem conexões e entrassem em composições com o que acontecia na rua frente as ações propostas, eles fizeram notar esses pontos que são de maior tensão, produzindo encontros de forças que promoveram afetos da produção estética vinculada ao presente e aos acontecimentos.

A potência educativa que apostamos nesta performance está na abertura a um desvio, em que uma função-educador pôde operar na vinculação com o presente, funcionando como acontecimento e engendrando outras relações com a existência, outras possibilidades de vida, remanejando a própria proposta performática e vinculando-a à imanência instável da vida.

A performance Cariogamia e o risco do aborto atuou na experimentação dos territórios de vida e nas práticas de convívio já estabelecidas na cidade, produzindo pequenos espaçamentos e pequenos vazamentos, fugas no próprio território, a partir de experiências afetivas na relação do corpo com o urbano como condição para uma invenção de si e do mundo. 


\section{Referências}

CARVALHO, A. F. de. Foucault e a função educador: sujeição e experiências de subjetividades ativas na formação humana. Ijuí: Ed. Unijuí, 2010.

DELEUZE, G.; GUATTARI, F. Proust e os signos. Trad. PIQUET, A. C. ; MACHADO, R. 1. ed. Rio de Janeiro: Forense, 1987.

DELEUZE, G.; GUATTARI, F. Diferença e repetição. Trad. ORLANDI, L.; MACHADO, R. São Paulo: Graal, 1988.

DELEUZE, G.; GUATTARI, F. O que é filosofia? Trad. PRADO Jr, B.; MUNOS, A. A. Rio de Janeiro: Editora 34, 1992.

DELEUZE, G.; GUATTARI, F. Mil Platôs: capitalismo e esquizofrenia. v. 1.Trad. GUERRA NETO, A.; COSTA, C. P. São Paulo: Ed. 34, 1995.

DELEUZE, G.; GUATTARI, F. Mil Platôs: capitalismo e esquizofrenia.v. 3. Trad. GUERRA NETO, A.; OLIVEIRA, A. L. de; LEÃO, L. C.; ROLNIK, S. São Paulo: Ed. 34, 1996.

DELEUZE, G.; GUATTARI, F. Mil Platôs: capitalismo e esquizofrenia. v. 5. Trad. PELBART, P. P.; CAIAFA. J. São Paulo: Ed. 34, 1997.

DELEUZE, G.; GUATTARI, F. Mil Platôs: capitalismo e esquizofrenia. v. 4. Trad. ROLNIK, S. São Paulo: Ed. 34, 2002.

GUATTARI, F. Caosmose: um novo paradigma estético. Trad. OLIVEIRA, A. L. de; LEÃO, L. C. São Paulo: Ed. 34, 1992.

GOLDBERG, R. A arte da performance: do futurismo ao presente. Trad. CAMARGO, J. L. São Paulo: Martins Fontes (Coleção a), 2006.

KASTRUP, V.A invenção de si e do mundo: uma introdução do tempo e do coletivo no estudo da cognição. Belo Horizonte: Autêntica, 2007.

ORLANDI, L. B. L. Deleuze: entre caos e pensamento. In: AMORIM, A. C. de R.; GALLO, S.; OLIVEIRA Jr., W. M. (Org.). Conexões: Deleuze e imagem e pensamento e..., Petrópolis, RJ: De Petrus; Brasília, DF: CNPq, 2011, p. 145-154.

SCHIMMEL, P. Out of actions: between performance and the object $1949-1979$. Los Angeles: Tharus and Hudson, The Meseum of Contemporary Art, 1998.

\section{Notas}

\footnotetext{
${ }^{1}$ Possuímos os direitos de exibição de todas as imagens apresentadas neste artigo.

${ }^{2}$ http://catarse.me/pt/BaixoCentro2013.

${ }^{3}$ O I Seminário Conexões realizado pela Faculdade de Educação da Unicamp intitulado "Deleuze e Imagem e Pensamento e...”, em 2012 encontra-se na sua 4a edição. O texto de Orlandi, Luiz B. L. foi publicado em Amorim, A. C.; Gallo, S.; Oliveira Jr., W.M. (Org.). In: Conexões: Deleuze e Imagem e Pensamento e..., Petrópolis: De Petrus; Brasília, DF: CNPq, 2011, p. 145-154.

${ }^{4}$ Termo de Gilles Deleuze e Félix Guattari (1995) citado em Mil Platôs: capitalismo e esquizofrenia - vol. I. Afirmam que a linha de fuga permite explodir o que está estratificado no interior do próprio processo, fazer vazar o que está organizado e passar a proceder por conexões.
} 
Juliana Soares Bom Tempo

* Doutoranda da Universidade Estadual de Campinas, Campinas, São Paulo - Brasil.

\section{Correspondência}

Juliana Soares Bom Tempo - Rua Tapajos, n. 1021, Saraiva. CEP 38408-414. Uberlândia - Minas Gerais. Brasil.

E-mail: ju_bomtempo@yahoo.com.br

Recebido em 30 de maio de 2014

Aprovado em 11 de agosto de 2014 